\title{
Clinical picture of community-acquired Chlamydia pneumoniae pneumonia requiring hospital treatment: a comparison between chlamydial and pneumococcal pneumonia
}

\author{
Maritta T Kauppinen, Pekka Saikku, Pekka Kujala, Elja Herva, Hannu Syrjälä
}

National Public Health Institute, Department in Oulu, Oulu, Finland M T Kauppinen P Saikku

E Herva

H Syrjälä

Department of Hospital Infection Control

H Syriälä

Department of Internal Medicine, Division of Infectious Diseases P Kujala

Clinical Microbiology Laboratory M T Kauppinen

Oulu University Hospital, Oulu, Finland

Correspondence to: Dr M T Kauppinen, Clinical Microbiology Laboratory, Kajaaninitie 50 FIN-90220 Oulu, Finland.

Received 1 February 1995 Returned to authors Returned to a
1 June 1995 Revised version received 27 July 1995 27 July 1995 Accepted for publication 3 October 1995

\begin{abstract}
Background - The importance of Chlamydia pneumoniae as a cause of pneumonia has remained controversial. The clinical picture of $C$ pneumoniae and Streptococcus pneumoniae in patients admitted to hospital with communityacquired pneumonia was compared during a $C$ pneumoniae epidemic in Finland. Methods - Group I consisted of 24 patients in whom serological testing and bacterial culture indicated an association with $C$ pneumoniae only, group II comprised nine patients with both $C$ pneumoniae and $S$ pneumoniae, and group III consisted of 13 patients with $S$ pneumoniae only.

Results - The patients with $C$ pneumoniae suffered from headache more frequently than the other patients (group I, 46\%; group II, 11\%; and group III, 15\%) and had received antimicrobial treatment more often before admission to hospital (group I, 54\%; groups II and III, $0 \%$ ). The patients with $C$ pneumoniae produced few good sputum samples and had suffered from respiratory symptoms longer than those with $S$ pneumoniae (group I, 10 days; groups II and III, 4 days). C reactive protein values on admission were lowest in group I and highest in group II. The antimicrobial treatment provided in hospital covered $C$ pneumoniae in $36 \%$ of cases in group $I$ and $0 \%$ in group II, while $S$ pneumoniae was covered in all patients. $C$ pneumoniae and $S$ pneumoniae together were associated with more severe disease and a longer stay in hospital.

Conclusions - Pneumonia caused by $C$ pneumoniae was milder but clinically resembled that caused by $S$ pneumoniae, and required hospital treatment even among young patients. Mixed infections were common and should be taken into account when planning antimicrobial treatment for community-acquired pneumonia. Further studies with more patients are needed to evaluate the severity of $C$ pneumoniae pneumonia.

(Thorax 1996;51:185-189)
\end{abstract}

Keywords: Chlamydia pneumoniae, community-acquired pneumonia, clinical signs.

Chlamydia pneumoniae, the third member of the genus Chlamydia, causes both upper respiratory tract infections such as sinusitis, pharyngitis, and otitis media, and lower respiratory tract infections, bronchitis and pneumonia. ${ }^{12}$ It is the cause of at least $10 \%$ of all cases of communityacquired pneumonia treated either in outpatient clinics or in hospitals..$^{3-5}$ In previous reports on the clinical picture of pneumonia caused by $C$ pneumoniae, patients have usually been young - for example, teenagers at vocational schools, university students, or military recruits - and the onset of pneumonia has been slow, starting with upper respiratory symptoms such as pharyngitis with hoarseness followed by cough and other lower respiratory symptoms. ${ }^{4-10}$ During epidemics among military recruits in Finland, only about $10 \%$ of $C$ pneumoniae infections manifested themselves as pneumonia. ${ }^{8}$ Since most $C$ pneumoniae infections are mild or even asymptomatic, its importance as a respiratory pathogen has been neglected. ${ }^{1112}$

In Finland $C$ pneumoniae caused a widespread epidemic in 1986-7 which was verified both serologically and by the presence of $C$ pneumoniae in respiratory samples in culture and by the polymerase chain reaction. ${ }^{101314}$ At the same time a prospective study of the aetiology of community-acquired pneumonia requiring hospital treatment was carried out at Oulu University Hospital in northern Finland. During this period $C$ pneumoniae closely followed Streptococcus pneumoniae in frequency as an aetiological agent for pneumonia, and this provided us with a unique opportunity to investigate the clinical picture of patients with $C$ pneumoniae pneumonia and to compare it with that of pneumococcal pneumonia.

\section{Methods}

PATIENTS AND SPECIMENS

During the period between May 1986 and May 1987,125 adults with radiologically confirmed community-acquired pneumonia were admitted to the ward for infectious diseases at Oulu University Hospital, and paired serum samples were obtained for serological examination on admission and on discharge approximately one week later. A third serum sample was obtained from $72 \%$ of the 125 patients during a follow up visit approximately one month later. The patients who fulfilled the diagnostic criteria for pneumonia caused by $C$ pneumoniae and/or $S$ pneumoniae (see below) 
without any evidence of other causative agents formed the groups for comparison of the clinical picture.

\section{BACTERIOLOGICAL METHODS}

Two aerobic and anaerobic blood cultures (Hemobact, Orion Diagnostic, Finland) were obtained from all 125 patients on admission, before antimicrobial chemotherapy was started. One hundred and fifteen patients were able to produce a sputum sample for culture. The specimens were treated with $\mathrm{N}$-acetyl-L-cysteine and cultured semiquantitatively on blood, chocolate, and Legionella selective agar (BCYE) plates. ${ }^{15}$ Mycobacterium cultures were made on Löwenstein-Jensen medium with and without pyruvic acid. The quality of the sputum sample was assessed by the method of Bartlett et al and graded as good, moderate or poor. ${ }^{16}$ The culture results were accepted as aetiologically indicative if the growth from a good or moderate quality sputum sample was heavy or moderate. ${ }^{16}{ }^{17}$ Such growth of Haemophilus influenzae, Moraxella (Branhamella) catarrhalis, Staphylococcus aureus, or Gram negative bacilli in cases of pneumococcal or chlamydial pneumonia was considered to indicate mixed infection. No culture result from a poor quality sputum sample was accepted.

Pneumococcal capsular antigens were sought from 109 of 115 sputum samples utilising a latex agglutination reagent prepared from polyvalent pneumococcal Omniserum (Staten's Serum Institute, Copenhagen, Denmark). ${ }^{18}$

SEROLOGICAL METHODS

Chlamydial antibodies were measured by the microimmunofluorescence method using the following elementary bodies as antigens: $C$ pneumoniae AR 39 and/or Kajaani 6 (epidemic) strains, $C$ trachomatis pools of immunotypes $\mathrm{CHIJ}, \mathrm{GFK}, \mathrm{BDE}$, and $C$ psittaci $\mathrm{OA}$ and 6BC strains. ${ }^{1019}$ All IgM positive serum samples indicating primary infection were retested after treatment with Gullsorb (Gull Laboratories, USA) to avoid false positive IgM findings due to rheumatoid factor. ${ }^{310}$ The complement fixation method was used to measure antibodies to Mycoplasma pneumoniae, influenza $\mathrm{A}$ and $\mathrm{B}$, parainfluenza 1,2 , and 3 , respiratory syncytial virus, adenovirus, measles, herpes simplex, varicella zoster, cytomegalovirus, parotitis, and coxsackie (B5) virus. Antibodies to Legionella were measured by indirect immunofluorescence and those to $S$ pneumoniae, $H$ influenzae, and $M$ catarrhalis by enzyme immunoassay. ${ }^{151720}$ The serological criterion used in enzyme immunoassay testing was a threefold increase in antibodies.

DIAGNOSTIC CRITERIA FOR PNEUMONIA CAUSED BY C PNEUMONLAE

A fourfold or greater rise in titre in any Ig class of antibodies to $C$ pneumoniae between paired serum samples or an IgG titre of $\geq 512$, an IgA titre of $\geq 512$, or the presence of $\operatorname{IgM}$ $(\geq 16)$ antibodies in any serum sample were considered diagnostic for pneumonia caused by $C$ pneumoniae. ${ }^{19}$ Only clearcut even fluorescence of elementary bodies specific for $C$ pneumoniae was accepted, and any case with evidence of cross reactivity was excluded. ${ }^{21}$ The presence of IgM class antibodies on admission was considered to be a mark of primary infection. Other positive findings were considered reinfections.

DIAGNOSTIC CRITERIA FOR PNEUMONIA CAUSED BY $S$ PNEUMONIAE

$S$ pneumoniae was considered a pathogen when isolated from blood culture or verified both bacteriologically and serologically. The bacteriological criterion was isolation from a sputum specimen of good or moderate quality (see methods) showing Gram positive diplococci in a Gram stained smear and/or a positive pneumococcal capsular antigen, and the serological criteria were either a twofold or greater increase in antibodies to pneumolysin or the presence of pneumolysin-specific immune complexes in any serum sample. ${ }^{2223}$

\section{CLINICAL SYMPTOMS AND LABORATORY} PARAMETERS

The following clinical data were analysed: symptoms, pre-existing chronic conditions, physical examination, clinical laboratory findings, responses to antimicrobial treatment, duration of hospital stay, and outcome. The laboratory parameters included white blood cell count (WBC, $\left.\times 10^{9} / 1\right)$ with differential counts, erythrocyte sedimentation rate (ESR, $\mathrm{mm} / \mathrm{h}$ ), plasma sodium, potassium, albumin, creatinine, calcium, aspartate transaminase (ASAT), alanine transaminase (ALAT), bilirubin, alkaline phosphatase, creatine kinase, and cholesterol. C reactive protein (CRP, mg/l) was analysed by an immunoturbidometric method. $^{24}$

\section{DATA ANALYSIS}

Continuous variables were analysed statistically by one way analysis of variance (ANOVA) and the Student's $t$ test and non-continuous variables by the $\chi^{2}$ test using SPSS for Windows. ${ }^{25}$ If the number of findings was less than five, Fisher's exact test was used.

\section{Results}

Forty six of the 125 patients were classified on the strict criteria as belonging to one of the three groups. In 24 cases the pneumonia was caused by $C$ pneumoniae alone (group I), five of whom had an IgM positive primary infection and 19 had a reinfection; in nine cases the pneumonia was caused by $S$ pneumoniae and $C$ pneumoniae together (group II), two of whom had an IgM positive $C$ pneumoniae primary infection and seven a reinfection, and two had pneumococcal bacteraemia; and in 13 cases the pneumonia was caused by $S$ pneumoniae alone (group III) including eight who had pneumococcal bacteraemia. 
Table 1 Characteristics and major symptoms of the patients in the three aetiological groups of pneumonia

\begin{tabular}{llll}
\hline Features & $\begin{array}{l}\text { Group I } \\
\text { Cpneumoniae } \\
(n=24)\end{array}$ & $\begin{array}{l}\text { Group II } \\
\text { Both agents } \\
(n=9)\end{array}$ & $\begin{array}{l}\text { Group III } \\
\text { S pneumoniae } \\
(n=13)\end{array}$ \\
\hline Male & 14 & 4 & 7 \\
Smoking & 10 & 4 & 3 \\
Alcoholism & 1 & 1 & 2 \\
Any underlying condition & 9 & 6 & 9 \\
Antibiotic treatment before admission* & 13 & 0 & 0 \\
Fever at home & 22 & 8 & 13 \\
Respiratory symptoms: & 19 & 8 & 10 \\
Cough & 17 & 9 & 12 \\
Sputum production & 3 & 1 & 2 \\
Haemoptysis & 8 & 6 & 6 \\
Shortness of breath & 6 & 1 & 1 \\
Chest pain & 4 & 0 & 2 \\
$\quad$ Sinusitis or otitis & 13 & 1 & 0 \\
CNS symptoms & 11 & 1 & 2 \\
$\quad$ Headache & 2 & 0 & \\
Confusion & 2 & 2 & \\
Diarrhoea & & & \\
\hline
\end{tabular}

$* p<0.001 ; \uparrow p<0.05$

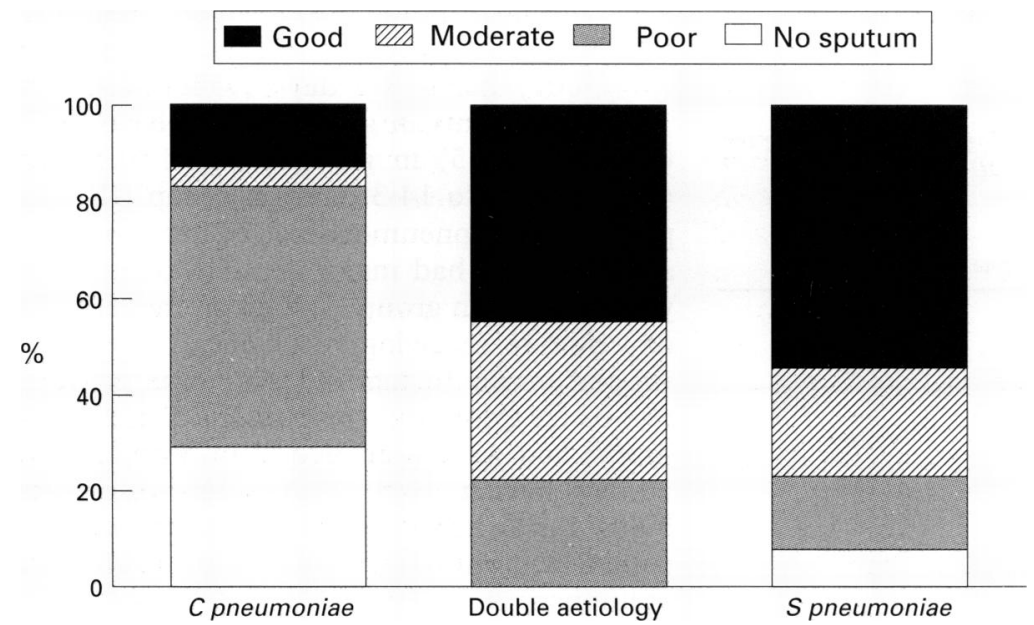

Figure 1 Sputum production and purulence of the specimen. Group $I=C$ pneumoniae only; group II=double aetiology; group III=S pneumoniae only.

COMPARISON OF CLINICAL DATA

Table 1 shows that the three aetiological groups did not differ significantly in terms of sex, smoking, alcohol abuse, or underlying clinical diseases (asthma, chronic obstructive pulmonary disease, diabetes mellitus, chronic coronary heart disease, heart failure, hypertension, dementia, immunosuppression, haematological malignancy or other tumour). The patients in group I were about 15 years older on average than those in group II, but the difference did not reach statistical significance $(62.2(95 \%$ CI $52 \cdot 2$ to $72 \cdot 2)$ versus 53.2 (95\% CI $44 \cdot 3$ to $61 \cdot 1)$ ). The prevalence of respiratory symptoms was similar in the three groups (table 1). Almost half of the patients in group I complained of a headache, whereas the corresponding figures for groups II and III were $15.4 \%$ and $11 \cdot 1 \%$, respectively $(p=N S)$. The patients in group I produced sputum less frequently and the quality of the specimen was poor compared with the other groups, and only a few purulent sputum samples were obtained $(p<0.01$, fig 1). Interestingly, $52 \%$ of the patients in group I had received antibiotic treatment before entering hospital, compared with none in the other two groups $(\mathrm{p}<0.0005)$. However, this did not influence the sputum purulence results in group I. Of the 13 patients who received antibiotic treatment prior to admission, two could not produce any sputum and nine had sputum of poor quality, while the corresponding figures for patients who did not receive antibiotics were five and four, respectively.

As shown in table 2, the patients in group I had a longer duration of respiratory symptoms than the other two groups $(p<0.01)$, whereas the duration of fever varied only from three to four days between the groups. Physical examination conducted on admission did not reveal any differences between the three groups. Both the patients in group I and those with pneumococcal pneumonia showed a clear correlation between pulse rate and body temperature $(r=0.48, \mathrm{p}<0.05$ and $r=0.52, \mathrm{p}=$ 0.01 , respectively). Chest auscultation revealed pneumonic rales in $100 \%$ of the cases in the patients in group III, and in $78-80 \%$ of the two other groups $(p=N S)$. The most profound difference in the laboratory tests was seen in CRP values on admission, where patients in group II had the highest values and those in group I the lowest $(\mathrm{p}<0.005)$. The kinetics of CRP are shown in fig 2 . Both WBC $(p=N S)$ and CRP $(p<0.01)$ were highest in patients in group II on admission, while the CRP concentration was much higher on admission in patients in group III than in those in group I without any overlap in the $95 \%$ confidence

Table 2 Mean (95\% confidence interval) major physical and laboratory findings of the patients in the three aetiological groups of pneumonia on admission

\begin{tabular}{|c|c|c|c|}
\hline Features & $\begin{array}{l}\text { Group I } \\
\text { C pneumoniae } \\
(n=24)\end{array}$ & $\begin{array}{l}\text { Group II } \\
\text { Both agents } \\
(n=9)\end{array}$ & $\begin{array}{l}\text { Group III } \\
\text { S pneumoniae } \\
(n=13)\end{array}$ \\
\hline $\begin{array}{l}\text { Duration of symptoms (days)* } \\
\text { Duration of fever (days) }\end{array}$ & $\begin{array}{c}10 \cdot 5(6 \cdot 8 \text { to } 14 \cdot 1) \\
4 \cdot 1(2 \cdot 7 \text { to } 5 \cdot 4)\end{array}$ & $\begin{array}{l}4.0(1.7 \text { to } 6.3) \\
4.0(0.9 \text { to } 7.0)\end{array}$ & $\begin{array}{l}3.5(2 \cdot 1 \text { to } 4 \cdot 8) \\
3 \cdot 0(1.6 \text { to } 4 \cdot 3)\end{array}$ \\
\hline $\begin{array}{l}\text { Physical findings: } \\
\text { Blood pressure }(\mathrm{mm} \mathrm{Hg})\end{array}$ & & & \\
\hline $\begin{array}{l}\text { Systolic } \\
\text { Diastolic } \\
\text { Heart rate }(/ \mathrm{min}) \\
\text { Temperature }\left({ }^{\circ} \mathrm{C}\right)\end{array}$ & $\begin{array}{l}133(125 \text { to } 141) \\
75(70 \text { to } 80) \\
88(80 \text { to } 96) \\
38 \cdot 2(37 \cdot 7 \text { to } 38 \cdot 6)\end{array}$ & $\begin{array}{l}128(107 \text { to } 148) \\
69(59 \text { to } 78) \\
102(89 \text { to } 115) \\
38 \cdot 2(37 \cdot 1 \text { to } 39 \cdot 2)\end{array}$ & $\begin{array}{l}127(112 \text { to } 142) \\
70(65 \text { to } 75) \\
101(91 \text { to } 112) \\
38 \cdot 5(37 \cdot 9 \text { to } 39 \cdot 0)\end{array}$ \\
\hline $\begin{array}{l}\text { Laboratory findings: } \\
\text { ESR }(\mathrm{mm} / \mathrm{h}) \\
\text { C-reactive protein }(\mathrm{mg} / \mathrm{l})^{*} \\
\text { Creatinine }(\mu \mathrm{mol} / \mathrm{l}) \\
\text { Albumin }(\mathrm{g} / \mathrm{l}) \\
\text { WBC }\left(\times 10^{9} / 1\right) \\
\text { Granulocytes } \\
\text { Lymphocytes } \\
\text { Band forms }\end{array}$ & $\begin{array}{l}63(48 \text { to } 78) \\
107(78 \text { to } 135) \\
117(52 \text { to } 182) \\
35(33 \text { to } 37) \\
11.6(8.8 \text { to } 14 \cdot 6) \\
65.3(59 \cdot 7 \text { to } 71 \cdot 0) \\
23 \cdot 0(18 \cdot 3 \text { to } 27 \cdot 7) \\
3.5(1.3 \text { to } 5 \cdot 8)\end{array}$ & $\begin{array}{l}92(75 \text { to } 108) \\
193(98 \text { to } 287) \\
89(79 \text { to } 99) \\
31(26 \text { to } 36) \\
17.6(10.3 \text { to } 24.9) \\
66.9(51.6 \text { to } 82 \cdot 2) \\
17.2(8.8 \text { to } 25 \cdot 6) \\
8.6(1.4 \text { to } 15 \cdot 7)\end{array}$ & $\begin{array}{l}64(41 \text { to } 87) \\
179(143 \text { to } 215) \\
106(93 \text { to } 119) \\
34(30 \text { to } 38) \\
15 \cdot 6(11 \cdot 5 \text { to } 19 \cdot 6) \\
72 \cdot 1(61 \cdot 6 \text { to } 82 \cdot 5) \\
16 \cdot 6(8 \cdot 9 \text { to } 24 \cdot 4) \\
6 \cdot 6(2 \cdot 8 \text { to } 10 \cdot 4)\end{array}$ \\
\hline
\end{tabular}

$* \mathrm{p}<0 \cdot 001$. 


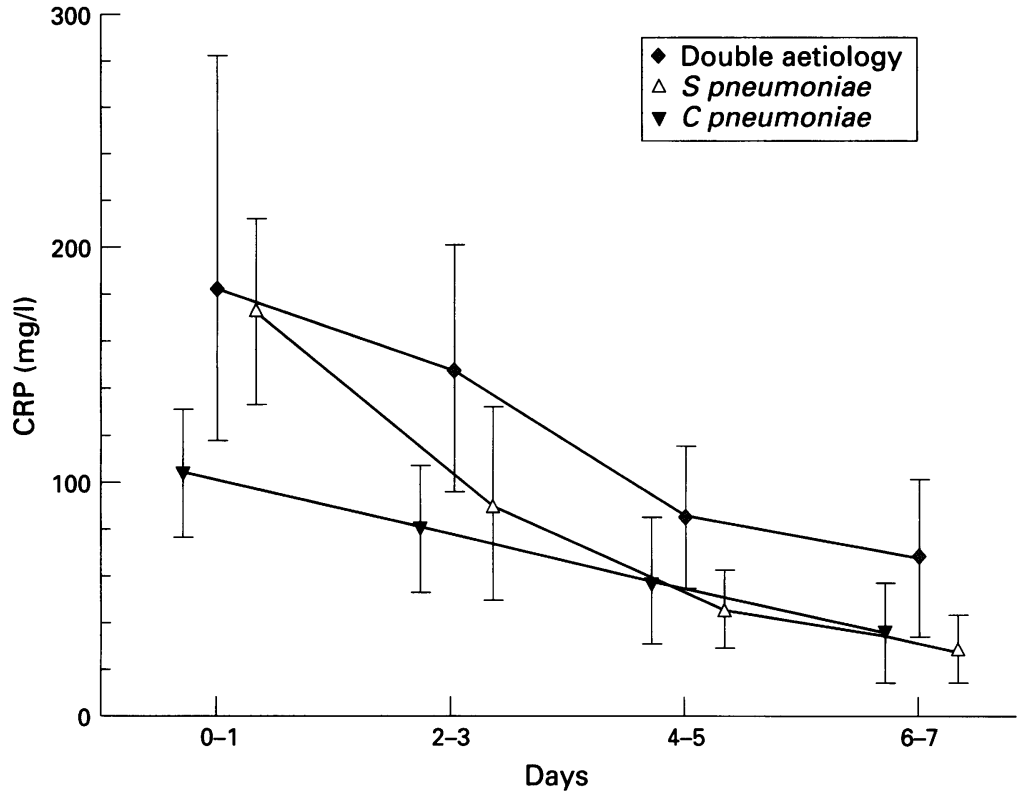

Figure 2 Kinetics of $C$ reactive protein (CRP) in the three aetiological groups during the first week of admission to hospital (mean, 95\% confidence interval).

Table 3 Antibiotic treatment in the three aetiological groups of pneumonia

\begin{tabular}{llll}
\hline Antibiotics & $\begin{array}{l}\text { Group I } \\
\text { C pneumoniae } \\
(n=25)\end{array}$ & $\begin{array}{l}\text { Group II } \\
\text { Both agents } \\
(n=9)\end{array}$ & $\begin{array}{l}\text { Group III } \\
\text { S pneumoniae } \\
(n=13)\end{array}$ \\
\hline $\begin{array}{l}\text { First antibiotic } \\
\quad \text { Penicillin }\end{array}$ & $14(56)$ & $3(33)$ & $9(69)$ \\
$\quad$ Cefuroxime & $10(40)$ & $6(67)$ & $4(31)$ \\
Penicillin only & $5(20)$ & $3(33)$ & $8(62)$ \\
Appropriate treatment* & $9(36)$ & $0 \ddagger$ & $13(100)$ \\
No of antibiotics used & $8(32)$ & $5(56)$ & $8(62)$ \\
1 & $14(56)$ & $2(22)$ & $4(31)$ \\
2 & $2(8)$ & $1(11)$ & 1 \\
3 & $1(4)$ & 0 & 0 \\
4 & 0 & $1(11)$ & 0 \\
\hline 4 & 0 & & \\
\hline
\end{tabular}

Values in parentheses are percentages.

* Group I: doxycycline or erythromycin; group II: penicillin or erythromycin or cefuroxime; group III: penicillin/cefuroxine and erythromycin/doxycycline.

$\dagger$ The change from penicillin $G$ to penicillin $V$ from cefuroxime to oral cephalexine was considered as one course.

$\ddagger$ All patients received appropriate treatment against $S$ pneumoniae but none against $C$ pneumoniae.

intervals. During the admission period the differences in parameters between the groups fell. White blood cells, their differential counts, and ESR did not differ between the groups, although the patients in group I had the lowest counts. The same was true for serum electrolytes, bilirubin, calcium, creatine kinase, cholesterol, and the liver function tests (data not shown). Increased alkaline phosphate levels $(>250 \mathrm{U} / \mathrm{l})$ were seen in five cases in group I and two cases in group III.

ANTIBIOTIC TREATMENT DURING HOSPITAL STAY Only $36 \%$ of the patients in group I received either doxycycline hydrochloride or erythromycin treatment (table 3), whereas all the patients in group III received penicillin G, cefuroxime, or erythromycin - that is, antibiotics that are active against $S$ pneumoniae. All the patients in the group II also received antibiotics active against $S$ pneumoniae, but none of them was treated with either doxycycline hydrochloride or erythromycin. The patients in group II received more courses of antibiotics than those in the other two groups.
The first antibiotic given was penicillin $G$ in more than half the cases in groups I and III, whereas in group II treatment was more often started with cefuroxime. When all the patients infected with $C$ pneumoniae were analysed together (groups I and II), nine of the 36 had received appropriate antimicrobial treatment, whereas all 13 patients with $S$ pneumoniae infection (group III) and nine of the patients infected with both organisms (group II) were treated with appropriate antibiotics against pneumococcus $(p<0.001)$. The importance of appropriate antimicrobial treatment was reflected by the faster decrease in CRP values observed in group III than in the other groups $(\mathrm{p}=\mathrm{NS}$, fig 2$)$

OUTCOME FOR PATIENTS WITH PNEUMONIA

The mean duration of hospital treatment differed significantly between the three groups $(\mathrm{p}=0.001$ ) being 8.4 days (95\% CI 6.7 to $10 \cdot 2)$ in patients in group $I, 21.9$ days (95\% CI 4.2 to $39 \cdot 5$ ) in group II, and 10.5 days (95\% CI 6.8 to $14 \cdot 3$ days) in group III. Two patients with pneumococcal bacteraemia and alcohol abuse had major complications. A 60 year old man in group III died on the eleventh day despite receiving mechanical respiratory support and a 36 year old woman in group II recovered from adult respiratory distress syndrome and was discharged from hospital after 70 days having received seven courses of antibiotic during her hospital stay. In addition, one patient without bacteraemia in group II had a pulmonary embolism.

\section{Discussion}

C pneumoniae pneumonia has been described previously as a mild atypical pneumonia which can be treated on an outpatient basis. ${ }^{711}$ Our results indicate that $C$ pneumoniae as a single aetiological agent is capable of causing pneumonia severe enough to require admission to hospital even in relatively young patients. The clinical picture, although milder, resembles that of pneumococcal pneumonia. Furthermore, $C$ pneumoniae and $S$ pneumoniae as a dual infection results in more severe illness with higher CRP values requiring longer hospital treatment than either $C$ pneumoniae or $S$ pneumoniae infection alone.

Among the clinical symptoms, headache was more common in the patients with $C$ pneumoniae pneumonia $(46 \%)$. The frequency of headache in earlier reports has varied from $17 \%$ to $60 \%$. $^{2451326}$ Central nervous system symptoms including headache seem to be common in $C$ pneumoniae pneumonia, which has also been seen with other atypical pneumonias. ${ }^{42627}$

The physical examination did not reveal any outstanding differences between the groups, as has been reported earlier. ${ }^{2728}$ Increased alkaline phosphate levels have been reported in association with $C$ pneumoniae pneumonia, but this was not evident in our patients. ${ }^{5}$ The relatively slow pulse rate in relation to the fever reported in association with other intracellular 
infections such as brucellosis, typhoid fever, legionellosis, and psittacosis was not seen in our patients with $C$ pneumoniae pneumonia.

$C$ pneumoniae was not recognised as a pathogen for pneumonia during the period of our study, and the ongoing $C$ pneumoniae epidemic was only demonstrated later. In the group of patients with $C$ pneumoniae infection six had received doxycycline and one erythromycin for a median of three days before admission to hospital. These treatments were changed to either penicillin $\mathrm{G}$ or cefuroxime on admission. All the patients in the $C$ pneumoniae group recovered, however, although only $36 \%$ had received the appropriate antimicrobial treatment (that is, erythromycin or tetracycline). Reports from North America have also mentioned that patients with $C$ pneumoniae pneumonia recovered without adequate antibiotic treatment. $^{2829}$ Current guidelines for community-acquired pneumonia stress the importance of $C$ pneumoniae as an aetiological agent and of prescribing macrolides which are also effective against other pathogens that cause community-acquired pneumonia such as $S$ pneumoniae, $M$ pneumoniae, and $L$ pneumophila. ${ }^{30}$

Patients with $C$ trachomatis or $C$ psittaci infections also respond to treatment with $\beta$ lactam antibiotics. ${ }^{3132}$ The duration of fever in psittacosis has nevertheless been longer during treatment with $\beta$ lactams than with tetracycline or erythromycin. ${ }^{31}$

The patients with both $C$ pneumoniae and $S$ pneumoniae infections received the appropriate treatment for $S$ pneumoniae but not for $C$ pneumoniae, which may account for their longer period in hospital. The severe clinical picture associated with simultaneous pneumococcal and $C$ pneumoniae infections emphasises the importance of rapid diagnostic methods such as the polymerase chain reaction for the identification of pathogens. ${ }^{334}$ Furthermore, these rapid diagnostic methods should be used together as the demonstration of one aetiological agent does not exclude others, for which different antibiotic treatments may be needed.

1 Macfarlane JT, Finch RG, Ward MJ, Macrae AD. Hospital study of adult community-acquired pneumonia. Lancet 1982;ii:255-8.

2 Fang G-D, Fine M, Orloff J, Arisumi D, Yu VL, Kapoor $\mathrm{W}$, et al. New and emerging etiologies for communityacquired pneumonia with implications for therapy. A proacquired pneumonia with implications for therapy. A pro69:307-16.

3 Grayston JT, Campbell LA, Kuo CC, Mordhorst $\mathrm{CH}$, Saikku P, Thom DH et al. A new respiratory tract pathogen: Chlamydia pneumoniae strain TWAR. $\mathcal{F}$ Infect $D i$ 1990;161:618-25.

4 Thom DM, Grayston JT, Wang SP, Kuo CC, Altman J. Chlamydia pneumoniae, strain TWAR, Mycoplasma pneumoniae and viral infections in acute respiratory disease in moniversity student health clinic population. Am $¥$ Epidemiol 1990;132:248-56.

5 Sundelöf B, Gnarpe J, Gnare H, Grillner L, Darougar S. Chlamydia pneumoniae in Swedish patients. Scand $\mathcal{F}$ Infect Dis 1993;25:429-33.

6 Saikku P, Wang SP, Kleemola M, Brander E, Rusanen E, Grayston JT. An epidemic of mild pneumonia due to an unusual

7 Grayston JT, Kuo CC, Wang SP, Altman J. A new Chlamydia psittaci strain, TWAR, isolated in acute respiratory tract infections. N Engl f Med 1986;315:161-8.
8 Kleemola M, Saikku P, Visakorpi R, Wang SP, Grayston JT. Epidemics of pneumonia caused by TWAR, a new Chlamydia organism, in military trainees in Finland. $\mathcal{f}$ Infect Dis 1988;157:230-6.

9 Berdal BP, Scheel O, Ogaard AR, Hoel T, Gutteberg TJ, Anestad G. Spread of subclinical Chlamydia pneumoniae infection in a closed community. Scand f Infect Dis 1992; infection in

10 Ekman MR, Grayston JT, Visakorpi R, Kleemola M, Kuo pre, Saikku P. An epidemic of infections due to Chlamydia preumo-5.

11 Hammerschlag MR. Chlamydia pneumoniae infections. Infect Med 1994;11:64-70.

12 Chirgwin K, Roblin PM, Gelling M, Hammerschlag MR, Schachter J. Infection with Chlamydia pneumoniae in Brooklyn. F Infect Dis 1991;163:757-61.

13 Ekman MR, Leinonen M, Syrjälä H, Linnanmäki E, Kujala P, Saikku P. Evaluation of serological methods in the diagnosis of Chlamydia pneumoniae during an epidemic in Finland. Eur $\mathcal{F}$ Clin Microbiol 1993;12:756-60.

14 Ekman MR, Rasmussen SJ, Timms P, Sarvas M, Saikku P. Polymerase chain reaction and indirect immunofluorescence for detection of Chlamydia pneumoniae. In: Abstracts of the 93rd ASM General Meeting, No. C-313. Abstracts of the 93rd ASM General

15 Edelstein PH. Diagnosis of infections caused by Legionellae. Eur f Clin Microbiol 1987;6:4-10.

16 Bartlett JG, Finegold SM. Bacteriology of expectorated sputum with quantitative culture and wash technique compared to transtracheal aspirates. Am Rev Respir Dis 1978;117:1019-27.

17 Kalin M, Lindberg AA, Tunevall G. Etiological diagnosis of bacterial pneumonia by Gram stain and quantitative culture of expectorates. Scand F Infect Dis 1983;75:109-18.

18 Holloway Y, Boersma WG, Kuttschrútter H, Snijder JA. Minimum number of pneumococci required for capsular antigen to be detectable by latex agglutination. $\mathcal{\exists}$ Clin Microbiol 1992;30:517-9.

19 Wang SP, Grayston JT. Microimmunofluorescence serological studies with the TWAR organism. In: Oriel JD, Ridgeway G, Schachter J, Taylor-Robinson D, Ward M, eds. Chlamydial infections. Cambridge: Cambridge Unieds. Chlamydial infections. Can

20 Leinonen M, Luotonen J, Herva E, Valkonen K, Mäkelä $\mathrm{PH}$. Preliminary serologic evidence for a pathogenic role of Branhamella catarrhalis. F Infect Dis 1981;144:570-4.

21 Grayston JT, Golubjatnikov R, Hagiwara, Hahn DL, Leinonen M, Persson K et al. Serologic tests for Chlamydia pneumoniae (letter). Pediatr Infect Dis $\mathcal{f} 1993 ; 12: 790-1$.

22 Leinonen M, Syrjälä H, Jalonen E, Kujala P, Herva E. Demonstration of pneumolysin antibodies in circulating immune complexes - a new diagnostic method for pneumococcal pneumonia. Serodiagn Immunother Infect Dis 1990;4:451-8.

23 Jalonen E, Paton JC, Koskela M, Kerttula Y, Leinonen M. Measurement of antibody responses to pneumolysin: a promising method for the presumptive etiological diagpromising method for the presumptive etiological diag-
nosis of pneumococcal pneumonia. $\mathcal{F}$ Infect 1989;19:12734 .

24 Harmoinen A, Perko M, Gröönroos P. Rapid quantitative determination of C-reactive protein using LKB 8600 reaction rate analyzer. Clin Chim Acta 1981;111:117-20.

25 SPSS for Windows. Base System User's Guide. Release 5.0. USA: SPSS Inc, 1992.

26 Frydén A, Kihlström E, Maller R, Persson K, Romanus V, Âhnsén S. A clinical and epidemiological study of "ornithosis" caused by Chlamydia psittaci and Chlamydia pneumoniae (strain TWAR). Scand $\mathcal{f}$ Infect Dis 1989;21: 681-91.

27 Helms CM, Viner JP, Sturm RH, Renner ED, Johnson W. Comparative features of pneumococcal, mycoplasmal, and Legionnaires' disease pneumonias. Ann Intern Med 1979; 90:543-7.

28 Grayston JT, Diwan VK, Cooney M, Wang SP. Communityand hospital-acquired pneumonia associated with Chlaand hospital-acquired pneumonia associated with Chlamydia TWAR dem

29 Marrie TJ, Grayston TJ, Wang SP, Kuo CC. Pneumonia associated with TWAR strain of Chlamydia. Ann Intern Med 1987;106:507-11.

30 American Thoracic Society. Medical section of the American Lung Association. Guidelines for the initial management of adults with community-acquired pneumonia: diagnosis, assessment of severity, and initial antimicrobial therapy. Am Rev Respir Dis 1993;148:1418-26.

31 Hammers-Berggren S, Granath F, Julander I, Kalin M Erythromycin for treatment of ornithosis. Scand f Infect Dis 1991;23:159-62.

32 Sweet RL, Schachter J, Robbie MO. Failure of beta-lactam antibiotics to eradicate Chlamydia trachomatis in the endometrium despite apparent clinical cure of acute salpinmetrium despite apparent clinica
gitis. $\Im A M A 1983 ; 250: 2641-5$.

33 Gaydos CA, Eiden JJ, Oldach D, Mundy LM, Auwaerte P, Warner ML, et al. Diagnosis of Chlamydia pneumoniae infection in patients with community-acquired pneumonia by polymerase chain reaction enzyme immunoassay. Clin Infect Dis 1994;19:157-60.

34 Gillespie SH, Ullman C, Smith MD, Emery V. Detection of Streptococcus pneumoniae in sputum samples by PCR. $\mathcal{I}$ of Streptococcus pneumoniae in sp
Clin Microbiol 1994;32:1308-11. 